\title{
Improving Learning Equity through a Social Constructivist Approach to Teaching and Learning: Insights from the Vygotskian Socio-Cultural Approach
}

\author{
Edmore Mutekwe \\ Vaal University of Technology, Faculty of Human Sciences, South Africa \\ Email: edmorem@vut.ac.za
}

\section{Doi:10.5901/mjss.2014.v5n27p1093}

\begin{abstract}
The purpose of this conceptual paper is to examine how the socio-cultural approach to teaching and learning can be used as a vehicle for promoting a meaningful and purposeful understanding of learning equity in the school and classroom. The paper thus unravels the following conceptual frameworks, embodied in the socio-cultural approach to learning and development to show how they can be used to buttress equitable learning among students: mediated learning experiences (MLE), situated learning; scaffolding, the zone of proximal development (ZPD); transforming students' skills from lower to higher mental functions; the use of learning tools; the use of indigenous knowledge systems (IKS) and the use of learning conversations (LC) in the classrooms.
\end{abstract}

Keywords: Mediated learning experiences, indigenous knowledge, lower mental functions, scaffolding, learning conversations

\section{Introduction and Background to the Study}

Contemporary educational practice has adopted a paradigm shift from traditional 'jug and mug' pedagogies towards modern progressive constructivist approaches that foster learning equity in the classroom. Social constructivism is defined by Mutekwe, Machingambi, Maphosa, Ndofirepi and Wadesango (2013) as an epistemology that foregrounds the social construction of knowledge through interactive teaching and learning activities in the classroom. It undergirds the importance of knowledge as a product co-constructed by the educators in meaningful interactions with the learners (Mutekwe et al., 2013). The pioneers of this approach to learning and development are Jean Piaget and Lev Vygotsky, whose cognitive and social constructivist theories respectively laid the foundation for what pedagogists now claim to be a formidable epistemology(). According to Mutekwe et al. (2013) social constructivism as a paradigm has the advantage of affording virtually all learners in the classroom with an opportunity to participate in interactive learning activities since it emphasises teaching and learning that draw from the learners' diverse socio-cultural backgrounds (Kozulin, 2002; Vygotsky, 1987). It is in this sense that the approach is hailed (Kozulin 2002) for promoting learning equity in the classroom.

As mentioned above, there has been a modern day global shift towards recognizing the importance of indigenous education. One reason for this current awareness is the rapid spread of Western educational models throughout the world (Odora-Hoppers, 2001). Starting in the 19th century when Native Americans were forced into U.S. government boarding schools up until today when volunteers build schools in various remote villages, there is a strong, and some might say blind, belief that a Western education or schooling is the only way to provide a better life for indigenous children. The film Schooling the World: The White Man's Last Burden addresses this issue of modern education and its destruction of unique, indigenous cultures and individuals' identities. In essence, the film examines the definitions of wealth and poverty and in other words, knowledge and ignorance. Furthermore, it reveals the effects of trying to institute a global education system or central learning authority, which can ultimately demolish traditional sustainable agricultural and ecological knowledge, in the breakup of extended families and communities, and in the devaluation of ancient spiritual values, beliefs and traditions (Sha 2014). Finally, the film promotes a deeper dialogue between cultures, suggesting that since there is no single way to learn, all learners need to be treated equally, fairly or in a just way in line with the thrust of learning equity globally (UNDRIP, 2012). Given that no two human beings are alike because they develop under different socialisation circumstances, learning and education, the need for learning equity becomes an imperative, which teaching and learning communities need to embrace regardless of the human diversities and the ethnocentric and xenocentric connotations that often accompany them across the globe (Black, 2012). 


\section{Promoting Learning Equity through a Social Constructivist Pedagogy}

The notion of learning equity as aptly described by van der Westhuizen (2009) and McGee Banks and Banks (2009) as a process of empowering all learners by affording them not only equality of educational opportunity but also ensuring that they receive fair treatment in their educational institutions. Learning equity thus involves establishing parity in the teaching and learning processes regardless of the diversity of the learners in terms of race, sex, gender, religion, social class, ethnicity, disability, culture or creed (Eisner, 2005). A variety of strategies for promoting learning equity in the classrooms have been identified by many theorists on this concept (e.g. McGee Banks \& Banks 2005; Darling-Hammond 2001; Eisner, 2005; van der Westhuizen 2009) and these include integrating all of the learners' cultural attributes in the social construction of knowledge, refraining from viewing them as empty vessels, considering them equal partners with their educators in the co-construction of knowledge; adopting equity pedagogies in the school and classrooms and avoiding stereotypes along such unreasonable grounds as race, sex, age, ethnicity, religion or disabilities.

According to van der Westhuizen's (2009) contention promoting learning equity in the classroom enhances meaningful learning and improves learning attainment. It is in this sense that his conceptualization of learning equity entails the quality of being just, equal, fair or impartial in the teaching or learning process. His view is shared by DarlingHammond (2001) who adds that learning equity as practice should regard all learners as equals irrespective of their diversities, differences or handicaps. The principle of learning equity in the classroom also foreground a balanced proportion and redistribution of power, access to material resources, rights and opportunities in all learning institutions (Eisner, 2005). This implies that the campaign for learning equity should not only be articulated through human rights declarative documents but also through educational policies and practices. Essentially this means advocating nondiscriminatory practices in the classrooms and schools, whether directly or indirectly against anyone on any one of the above cited grounds (Magano, Mostert \& van der Westhuizen, 2012). Among the tenets of learning equity are the needs to create a just, humane and democratic society. It embraces equity pedagogy and argues that equality of educational opportunity entails not just affording learners' equality of educational opportunity but also ensuring that they are treated in just or fair way within their institutions of learning (Magano et al., 2012). Learning equity is therefore crucial in all multicultural educational settings. To ensure learning equity becomes a reality, educators need to adopt the socio-cultural approach to teaching and learning and ensure that mediated learning experiences prevail in their classrooms (JohnSteiner \& Mahn, 2008).

\section{How Mediated Learning Experiences (MLE) Promote Learning Equity}

In the Vygotskian socio-cultural approach to learning and development, MLE describe learning situations facilitated by a go-between (mediator) who ensures that the learners understand the content at stake (Kozulin, 2002). A mediator in this sense is not only a human being such as a teacher, parent or more competent peer collaborator but can also be a tool or tools used to enhance an understanding of the concepts to be covered in the teaching and learning process (Wertsch, 2004). As mentioned above, the concept of mediation is central to Vygotsky's socio-cultural perspective. As a concept embodied in the social constructivist epistemology, it implies that all teaching and learning situations need to be mediated in one way or another. For Vygotsky (1987) there are basically three forms of mediators: material tools, psychological tools or other human beings (adult, parent, teacher or a more competent peer collaborator). The role of mediation in learning is therefore to scaffold and transform the learners' lower mental or cognitive functions to higher ones as the learner progresses from knowledge of one concept to the next as in being able to use a word processor to type documents such as letters to an advanced computer word processing phase such as mail merging, internet or sending a short message system (sms). Mediated learning experiences thus describe scaffolded learning situations where learners are taken through the paces to make them not just understand concepts but also to make them enjoy and partake in the co-construction and dissemination of knowledge (de Valenzuela 2009;Wertsch, 2004). Mediation thus involves the use of learning tools (material, psychological, semiotic and other human beings (Vygotsky, 1987). The objective of all forms of mediation is to ensure that every function in the learner's cultural development appears twice: first, on the social level, and later on the individual level or between people (inter-psychological), and then inside the learner (intra-psychological) (de Valenzuela, 2009). The mediation process thus starts in the home during early childhood as the child in the home is taught all sorts of ways to communicate with others and respond to environmental stimuli.

\section{Mediating Learning through Learning Tools}

According to the socio-cultural perspective, the process of mediating learning experiences allows for the learners' lower 
mental functions to be transformed into higher mental functions (John-Steiner \& Mahn, 2008). This requires the use of any of the three classes of mediators: material and psychological tools and other human beings. If carried out within the learners' zones of proximal development (ZPD), the mediation process is highly likely to yield heavy dividends in the learners themselves (Wertsch, 2008). Mediating learning in the learners' ZPD takes into account that every individual learner is perfectly able to achieve better with the help of a mediator (Kozulin, 2002). Therefore in relation to MLE the ZPD describes the difference between what learners can do on their own and what they can achieve with help of a mediator such as a teacher, parent or a more capable peer (De Valenzuela, 2009). Drawing on Vygotsky's concepts of lower and higher mental functions, the ZPD can thus be viewed as the distance between the learners' lower and higher mental functions, which they can overcome with the assistance of an adult, educator, parent or a more capable peer collaborator. Learning tools thus effectively mediate learning in the ZPD to adequately transform the learners' prior knowledge from lower to higher order cognitive levels (Wertsch, 2008). They are a form of mediators existing in various learning organizational cultures to get work accomplished (Tudge, 1990). Any physical artefacts (teaching aids) that an educator employs to enhance learner understanding in the classroom can be regarded as material tools. This includes such teaching media as lecture slides, transparencies, posters, charts, worksheets and all other things that are used to enhance learner understanding in the classrooms.

Another category of learning tools identified as crucial in MLE in the Vygotskian socio-cultural approach are what he (Vygotsky) termed psychological tools. These include what he regards as the most common types such as gestures, semiotics and language (de Valenzuela, 2009). This is taught from a very early age even before the child receives any formal education and from this, the child then learns how to communicate on a social level. The use of direct learning can be useful but in this regard, the mediator would somehow have to alter the environment (vaccinate) to make it more suitable for learning. Research has proven that the absence of a mediator in early childhood has a negative impact on the development of a child (Wertsch, 2008). It is thus through MLE in the school and classroom that the learners' lower mental or cognitive functions are transformed to higher mental or cognitive. No wonder proponents of Vygotskian sociocultural approach to learning and development (e.g. Hardman 2004; Kozulin, 2002; Wertsch, 2008; John-Steiner \& Mahn 2008) maintain that the learners' higher mental processes are functions of mediated learning activities.

\section{Fostering Learning Equity through the Use of Learning Conversations}

According to Magano et al (2012) learning conversations are verbal interactions that foster learning and development in learners. Examples include class discussions, seminars, debates, and drama and group discussions. From a Vygotskian socio-cultural perspective, learning conversations grounded in the learners' socio-cultural backgrounds and that respect their diversity have the power to contribute immensely towards learning equity because they empower all learners in the school or classroom (van der Westhuizen, 2009). They therefore need to be implemented in the school and classrooms if learners from diverse socio-cultural backgrounds are to be assisted to enjoy meaningful learning experiences. The current pedagogical thrust especially in the South African context of schooling is for educationists to embrace multicultural educational practices in the interest of complete inclusivity in the educational classrooms (de Valenzuela, 2009). Therefore carefully thought out learning conversations can go a long way towards promoting this goal or vision. It is in this light that this discussion regards learning conversations as amongst the most effective strategies for achieving learning equity by first providing the diverse learners with the support necessary for them to feel equally empowered and belonging (McGee Banks \& Banks, 2005). When motivated enough, they will then not only be able to do their best academically but will also start believing in themselves culminating in them being able to motivate others to follow suit (Darling-Hammond, 2001).

According to Wertsch (2008), adopting the above mentioned socio-cultural approach to learning has the potential to foster meaningful learning. As alluded to earlier on, the premises upon which this approach hinges include the view that learning awakens a variety of internal developmental processes that are able to operate only when the learners interact and it is in such interactions that they co-construct knowledge with their educators as mediators or facilitators (Kozulin, 2002). Learning, from this view is not synonymous with development through properly organized and mediated learning activities result in mental developments that set in motion a variety of further developmental processes that would not have been possible without social interactive processes (John-Steiner \& Mahn, 2008).

\section{How Situated Learning Approaches Foster Learning Equity}

Lave and Wenge (1998) have put forward an interesting account of how locating learning activities in social interactive activities helps learners develop some degree of social cohesion, which they describe as communities of practice. Their 
ideas were further developed by brown, Collins and Duguid (2009), who also maintain that one of the important ways through which diverse classrooms can become learning communities in which each participant makes significant contributions to the emergent understandings of all members, despite having unequal knowledge is through social interactive activities involving the use of the learners' every day experiences as the building blocks for their motivation. Brown et al. (2009) examine the role of what they termed reciprocal teaching, an approach in which learners and their educators take turns leading discussions about shared texts to foster structured dialogues and authentic learning communities of practice. For brown et al., (2009) such an approach enables positive conceptual changes in both the learners and their educators as they begin to share with each other well-defined tasks through questioning, clarifying, summarizing, and predicting issues in order to, for example, co-construct text-based knowledge. These approaches thus exemplify two themes in sociocultural approaches to classroom learning and teaching, the implementation of an educational program that allows for or encourages the co-construction of knowledge and the analysis of a learning programme that contributes to an understanding of classroom learning from a sociocultural perspective (John-Steiner \& Mahn, 2008).

Black (2012) maintains more often than not, in many non-modernized societies, situated learning experiences imply that children learn in a variety of ways, including free play or interaction with other multi-ethnic, multi-racial or multireligious children, immersion in nature, and directly helping adults with work and communal activities.-Essentially they learn by experience, experimentation, trial and error, by independent observation of nature and human behavior, and through voluntary community sharing of information, story, song, and ritual among other ways (Black, 2012). Most importantly, local elders and traditional knowledge systems are autonomous in comparison to strict Western education models (Aikman, 2003). Adults have very little control over children's moment-to-moment movements and choices. However, once learning is institutionalized and alienated from the learners' everyday experiences, both the freedom of the individual and his or her respect for the elder's wisdom are ruined (Pablo \& Rogoff, 2012). Family and community are sidelined as the teacher assumes all control over the child, while the school district has control over the teacher and the state has control over the district, and increasingly, systems of national standards and funding create national control over states (Pablo \& Rogoff, 2012). The above discussion implies that when indigenous knowledge is viewed as inferior to a standard school curriculum, an emphasis is thus placed on an individual's success in a broader consumer culture instead of on an ability to survive in his or her own environment. Black concludes with a comment, "We assume that this central authority, because it is associated with something that seems like an unequivocal good - 'education' - must itself be fundamentally good, a sort of benevolent dictatorship of the intellect (p119)." From a Western perspective, centralized control over learning is natural and consistent with the principles of freedom and democracy; and yet, it is this same centralized system or method of discipline that does not take into account the individual, which in the end stamps out local cultures. It is in view of this discourse that this paper argues for teaching and learning approaches that foster not just equality of educational opportunities but also equity or fairness in the way learners are treated when they get to their learning centres or institutions (Eisner, 2005). The next section discusses how indigenous knowledge systems can be used to further the learning equity agenda in the learning centres or classrooms.

\section{Using Indigenous Knowledge Systems to Advance the Learning Equity Agenda}

Indigenous knowledge systems focus specifically on teaching indigenous knowledge, models, methods, and content within formal or non-formal educational systems (Semali \& Kincheloe, 2009). The growing recognition and use of indigenous education methods can be a vehicle for promoting learning equity in education and a worthwhile response to the erosion and loss of indigenous knowledge systems that have resulted from the processes of colonialism, globalization, and modernity (Aikman, 2003;Sha, 2014). Integrating IKS in the school curriculum has the potential to make indigenous communities reclaim and revalue their socio-cultural traditions, languages, beliefs, attitudes and values and in so doing, improve the educational success of indigenous students, thus ensuring their respect, survival and integration into the global culture (Aikman, 2003).

Adopting collaborative learning experiences where the learners' IKS are used as prior learning experiences worth of recognition as part of their lower mental functions to be transformed to higher mental functions through MLE thus has the potential to go a long way towards increasing their desire for more interactive classrooms (Odora-Hoppers, 2011). This implies that for educators or mediators to promote learning equity through pedagogy, learning conversations adopted need to draw from the learners' IKS. In current applications of the sociocultural theory with emphasis on coparticipation, cooperative learning, and joint discovery, learners and educators need to bring their existing IKS so that they use them to co-construct new forms of knowledge in line with the constructivist approaches emphasized in today's teaching and learning paradigms (van der Westhuizen, 2009; Wertsch, 2008). Teaching and learning approaches that 
integrate the learners' IKS are highly likely to promote equitable learning in learners regardless of their diversity. Where indigenous knowledge learning tools are used to mediate learning (Pablo \& Rogoff, 2012) the potential for social harmony is higher than where unfamiliar learning tools are employed.

According to the United Nations Declaration on the Rights of Indigenous Peoples herein after abbreviated UNDRIP (2012), there has been an increasing global shift in educational trends toward recognizing and understanding indigenous models of education as a viable and legitimate form of promoting learning equity across such demographic indices as race, ethnicity, religion, gender, sex, culture or creed. Duane (2012) and UNESCO (2012) maintain that although there remains many different educational systems throughout the world, with some that are more predominant and widely accepted than others, many members of indigenous communities have begun to celebrate diversity in learning and see a global support for teaching and learning strategies that integrate traditional forms of knowledge as a huge success. Indigenous ways of knowing, learning, instructing, teaching, and training have been viewed by many postmodern scholars as important for ensuring that students and teachers, whether indigenous or non-indigenous, are able to benefit from education in a culturally sensitive manner that draws upon, utilizes, promotes learning equity and enhances awareness of indigenous traditions, beyond the standard Western curriculum of reading, writing, and arithmetic (Aikman, 2002; Holly, 2011).

The learning styles that children use in their indigenous learning systems are the same ones that occur in their community context (May \& Aikman, 2003). These indigenous learning styles often include: observation, imitation, use of narrative or storytelling, collaboration, and cooperation, as seen among African, American, Indian, Alaska Natives and Latin American communities (Sha, 2014). If adopted in line with the tenets of the social constructivist epistemology in the classroom, this form of hands-on approach of emphasizing direct experience and learning through inclusion has the potential to go a long way towards fostering learning equity in education (Deyhle \& Swisher, 2007). Under such learning approaches the learner feels that he or she is a vital member of the wider community, and is encouraged to participate in a meaningful way by fellow community members (Black, 2012). In many traditional educational societies, children often effectively learn skills through this system, without being taught explicitly or in a formal manner and this may differ from Western learning styles, which tend to include methods such as explicit instruction and testing and quizzing (Wilson, 2011). Creating an educational environment that is consistent with the learners' upbringing and the need for learning equity, rather than an education that follows strictly follows a traditionally Western format, allows for learners to retain knowledge more easily, because they learn in a way that recognises them as equals in society and this has a huge potential to yield success for them (Verna, 2011).

According to proponents of IKS such as Odora-Hoppers (2011) and Sefa and Rosenberg (2000), the structure of classrooms meant to promote learning equity by integrating IKS need to eliminate the distinction between the community and classroom and to make it easier for the students to relate to the material. Effective classrooms modeled along these principles should typically focus on group or cooperative learning strategies that provide an inclusive learning environment (Odor-Hoppers, 2011). A key factor for successful learning equity through integrating indigenous education practices is the student-teacher relationship (Black, 2012). Classroom settings to promote learning equity thus need to be socially constructed in a way that the teacher is able to share the control of the classroom with the students (Cornel, 2002). Rather than taking an authoritative role, the teacher should be viewed as a co-learner to the students, and both categories need to maintain a balance between personal warmth and the demands for academic achievement (UNESCO, 2012). For example, in such a classroom, students should be made to use group work activities and even be let to move freely about the classroom while working in order to consult with other students.

Other socio-cultural pedagogical strategies that can promote learning equity can be teachers minimizing soliciting an answer from an individual student, but rather encourage all of the students in the group to participate in classroom discourses (Sha, 2014). In this sense of communal learning, direct questions may be posed to the group as whole, and the control of learning conversations may not be the sole responsibility of the teacher. Such classrooms would also need to utilize open-ended questioning, inductive, analytical reasoning and verbalizations in group settings (Aikman, 2003).

Taken together, the following benefits accrue to learners as result of integrating IKS in to their school curriculum: For indigenous learners and instructors, the inclusion of these methods into schools often enhances educational effectiveness by providing an education that adheres to an indigenous person's own inherent perspectives, experiences, language, and customs, thereby making it easier for children to transition into the realm of adulthood (UNDRIP, 2012). For non-indigenous students and teachers, an education system that promotes learning equity often has the effect of raising awareness of individual and collective traditions surrounding indigenous communities and people in general, thereby promoting greater respect for and appreciation of various cultural realities (Cornel, 2002; UNESCO, 2012). In terms of educational content, the inclusion of indigenous knowledge within curricula, instructional materials, and textbooks has largely the same effect on preparing students for the greater world as other educational systems, such as 
the Western model (Duane, 2009; Wilson, 2011).

The aforementioned clearly shows there is value in integrating IKS in education in the public schooling system as it helps students of all backgrounds to benefit from being exposed to IKS. Furthermore, it can contribute to reducing such social ills as racism, sexism, tribalism, regionalism and even nepotism in the classroom and increase a people's sense of community in a diverse world (Black, 2012; Sefa \& Rosenberg, 2000). There are many sensitive issues about what can be taught and by whom that require responsible consideration by non-Indigenous teachers who appreciate the importance of interjecting IKS into standard mainstream schools (Semali \& Kincheloe, 2009). Concerns about misappropriation of IKS without recognizing the plight of indigenous people and giving back to them are legitimate (Semali \& Kincheloe, 2009). In situations where many educators are non-indigenous, and because indigenous perspectives seem to offer possible solutions for current and future social and economic problems of learning equity (Eisner, 2005), it is important for virtually all educators and agencies to develop curriculum and teaching strategies that promote not just equal opportunities but also equity in the interaction of learners and educators in institutions of learning. Odora-Hoppers (2011) suggests that one way to bring authentic learning equity to education is harness the advantages of the learners" indigenous knowledge experiences into the classroom and to work with community elders. This can help facilitate the incorporation of authentic indigenous knowledge and experiences into the classroom (Odora-Hoppers, 2001). This view is important for societies given that some indigenous people view education as an important tool to improve their situation by pursuing economic, social and cultural development (UNESCO, 2012). It provides them with individual empowerment and self-determination (Black, 2012). According to Sha 92014) integrating IKS in schools and classrooms has the advantages of socialising some indigenous people to be national assets to society by assimilation. Given that schooling has been explicitly and implicitly regarded as a site of rejection of indigenous knowledge and language and that it has been used as a means of assimilating and integrating indigenous peoples into a national society and identity at the cost of their indigenous identity and social practices incorporating it into the curriculum might go a long way raising a consciousness about its importance in nation building and transformation of communities (Odora-Hoppers, 2011). Wilson (2011) supports this view in his assertion that indigenous education and knowledge has a transformative power for indigenous communities that can be used to foster empowerment and justice. Therefore, the shift inn pedagogical practices towards recognizing indigenous models of education as legitimate forms is of utmost importance in UNDRIP's ongoing effort for indigenous rights, on a global scale.

\section{Conclusion}

The discussion in this paper has examined how mediated learning experiences, learning conversations, situated learning; indigenous knowledge systems can be used as vehicles for achieving learning equity. The approaches were explored as conceptual frameworks embodied in the social constructivist paradigm whose epistemology is underpinned by cooperative learning in an effort for mediators and learners to co-construct and share knowledge and experiences. The literature survey conducted for this paper has revealed that the aforementioned teaching and learning strategies have a huge potential to foster not only meaningful and purposeful learning but also to promote sustainable learning equity in educational institutions. Integrating indigenous knowledge systems in to the curriculum has also been viewed as a noble cause since it helps bring motivation to the teaching and learning processes by fostering not just equality of educational opportunities but also a sense of equity or fairness in the way students view their diversity and are viewed in their educational institutions.

\section{References}

Aikman, S. (2003). Indigenous Education: Addressing Current Issues and Developments. Comparative Education 39 (2): 139-145.

Black, C. (2012).Occupy Your Brain: On Power, Knowledge and the Re-occupation of Common Sense, Schooling the World Blog, August 27.

Brown, Collins, Duguid, (2009). Situated cognition and the culture of learning. Educational Researcher, 18 (1): 32-42

Cornel, P. (2002). Learning styles of American Indian/ Alaska Native Students: A Review of the Literature and Implications for Practice". Journal of American Indian Education 41 (3):13-17

Darling-Hammond, L. (2001). The right to learn and the advancement of teaching: Research, Policy and practice for democratic education. Educational Researcher, 25 (6):5-17

Deyhle, D \& Swisher, K. (2007). Research in American Indian and Alaska Native Education: From Assimilation to Self-Determination. Review of Research in Education 22: 113-194.

De Valenzuela, J. (2009). Socio-cultural views on learning: The SAGR Handbook of special education. London: Sage

Duane, C (2009). Contemporary Education. New York: United Nations State of the world's indigenous peoples 
Eisner, J. (2005). Learning equity in a university classroom. South African Journal of Higher Education 2 (1): 76-81

Hardman, J (2004). An Exploratory Case study of Computer use in a primary school mathematics classroom: New technology, New pedagogy. Perspectives in education 23 (4): 1-12

Holly, D.(2011).Re-inventing the One-room Schoolhouse: Merging Learner-Centered Pedagogy, Distance Education and Technology. Journal of Education technology, 23 (4); 131-133

John- Steiner, V. \& Mahn, H. (2008). Sociocultural Approaches to Learning \& Development: A Vygotskian framework. Educational Psychologist (34): 113-115

Kozulin, A. 2002). Psychological tools. A sociocultural approach to Education. Cambridge, Harvard University Press.

Magano, M, Mostert, P. \& Van der Westhuizen, G. (2012). Learning conversations. The value of interactive learning. Johannesburg: Heinemann

McGee Banks, C. \& Banks, J. (2005). Multi-cultural education in a modern classroom. Journal of Educational psychology, 3 (1): $61-73$

May, S. \& Aikman, S. (2003). Indigenous Education: Addressing current issues and developments. Comparative Education, 3(1):139145

Mutekwe, E., Machingambi, S., Maphosa, C., Ndofirepi, AP. \& Wadesango, N. (2013). A SWOT analysis of the rise of the social constructivist epistemology and its pedagogical implications in educational practice. The anthropologist: International journal of Studies of man, 15 (1): 53-65

Odora-Hoppers, C. (2011). Integrating indigenous knowledge in the curriculum. Paper presented at an Indigenous knowledge conference, Pretoria, HSRC, 24 August 2011

Odora-Hoppers, C. (2001). Indigenous knowledge systems and academic institutions in South Africa. Perspectives in education, 19 (1):73-85

Pablo, C. \& Rogoff, P. (2002). Schooling and Traditional Collaborative Social Organization of Problem Solving by Mayan Mothers and Children. Developmental Psychology 38 (1): 55-66

Sefa, D. \& Rosenberg, D.G. (2000). Indigenous Knowledge in Global Contexts: Multiple Readings of Our World Toronto: University of Toronto Press

Semali, L.M. \& Kincheloe, J.L. (2009). What is Indigenous Knowledge? New York: Falmer

Sha, Y. (2014). Learning in Adulthood: A Comprehensive Guide. San Francisco: Jossey-Bass

Tudge, J. (1990). Vygotsky, the Zone of Proximal Development, and Peer Collaboration: Implications for Classroom Practice. Chapter 6 in: Moll, L. C. Vygotsky and Education. Cambridge, Cambridge University Press (pp. 207-215)

UNESCO. (2012). Learning and Knowing in Indigenous Societies Today. UNESCO: World Bank.

United Nations Declaration on the Rights of Indigenous Peoples (2012). United Nations: World Bank publication

Van der Westhuizen, G. (2012). Learning equity in a University classroom. South African Journal of Higher Education, 26 (3):623-637

Verna. C. (2011). Silencing Aboriginal Curricular Content and Perspectives through multiculturalism: "There Are Other children Here." Review of Education, Pedagogy, and Cultural Studies, 33 (4), 306-317

Vygotsky, L.S. (1987). Mind in society: the development of higher psychological processes. Cambridge, MA: Harvard University Press

Wertsch, J. (2008). From social interaction to higher psychological processes: A clarification and application of Vygotsky's theory. Human development, 51:66-79

Wertsch, J. (2004). The construction of knowledge, Contributions to conceptual semantics. New York: Routledge

Wilson, T. (2011). Best Practices for Teaching Aboriginal Children: From an Aboriginal and Non-Aboriginal Perspective. Australian Journal of Education, 17 (4): 119-123 